\title{
Eigenbehaviors: identifying structure in routine
}

\author{
Nathan Eagle $\cdot$ Alex Sandy Pentland
}

Published online: 21 July 2009

(C) Springer-Verlag 2009

\section{Erratum to: Behav Ecol Sociobiol \\ DOI 10.1007/s00265-009-0739-0}

The original version of this article unfortunately contained a mistake. The received date was incorrect. Please note that the correct received date is September 192008.

The online version of the original article can be found at http://dx.doi. org/10.1007/s00265-009-0739-0

N. Eagle $\cdot$ A. S. Pentland

MIT Media Laboratory, Massachusetts Institute of Technology,

E15-383, 20 Ames St.,

Cambridge, MA 02139, USA

N. Eagle $(\bowtie)$

The Santa Fe Institute,

1399 Hyde Park Rd,

Santa Fe, NM 87501, USA

e-mail: nathan@mit.edu 